\title{
METABOLIC PATTERNS DURING PHYSIOLOGIC SLEEP: I. BLOOD GLUCOSE REGULATION DURING SLEEP IN NORMAL AND DIABETIC SUBJECTS *
}

\author{
By EUGENE D. ROBIN, DAVID M. TRAVIS, $\dagger$ DESMOND G. JULIAN AND \\ BURIS R. BOSHELL
}

\author{
(From the Department of Medicine, Harvard Medical School and the Medical Clinics of the \\ Peter Bent Brigham Hospital, Boston, Mass.)
}

(Submitted for publication July 12, 1959; accepted August 17, 1959)

Sleep is a time of varying physiologic and metabolic activity $(2,3)$. Many of the metabolic patterns which occur during sleep have not been well characterized. One area which falls into this category concerns the changes in blood glucose that occur during sleep. Previous studies on normal subjects have given conflicting results. Hyperglycemia, normoglycemia, and hypoglycemia have been reported to characterize sleep. Endres and Lucke (4) studied a group of adults and concluded that blood sugar rose during sleep. Similar results were reported by Chieffi and Rosselli del Turco (5) in a study of a group of children. Trimble and Maddock (6) studied capillary blood glucose concentrations in a group of nine normal young medical students. Their studies included eight isolated values taken during sleep and a series of values on a single subject taken at hourly intervals during an entire night's sleep. They concluded, although their data were inadequate for final conclusions, that blood glucose seemed to remain essentially constant during sleep. Dienst and Winter (7) reported that sleep was consistently associated with hypoglycemia and indeed that hypoglycemia was capable of inducing sleep. To our knowledge, no systematic study of blood glucose concentrations during sleep has been undertaken in a sizable group of subjects with diabetes mellitus.

Previous studies have had several limitations. Most workers have measured total blood-reducing substances rather than true glucose. The tech-

\footnotetext{
* This investigation was supported in part by a research grant (H-2243) from the National Heart Institute of the National Institutes of Health, United States Public Health Service, and in part from the Massachusetts Heart Association. Some of these data have been previously presented in abstract form (1).

$\dagger$ Public Health Service Research Fellow of the National Heart Institute.
}

nique of blood sampling has not allowed continuing sleep by the experimental subjects. Conclusions have generally been based on single or isolated blood glucose values occurring during sleep. The present study was designed to obviate these limitations and had as its objective an investigation of blood glucose regulation in normal and diabetic subjects during physiologic sleep.

\section{METHODS AND MATERIALS}

All subjects reported to the laboratory approximately four to six hours following the evening meal. A brachial vein was intubated with a No. 14 polyvinyl catheter so that blood could be obtained for analysis without distracting or waking the patient. A comfortable bed in a dark environment was provided. Thirty minutes after the catheter was in position, a control blood was obtained for glucose analysis. The subject was then permitted to fall asleep and hourly bloods were obtained during the entire night; upon his waking in the morning, a final sample of blood was obtained. No sedative drugs were used. Between sampling, the catheter was kept open by means of dilute heparin. Blood glucose concentrations were determined in some patients by the glucose oxidase method of Froesch and Renold (8), and in others by the method of Nelson (9). The glucose concentrations reported are therefore "true glucose" and not total reducing substances. The following studies were performed.

In eight normal subjects, hourly blood sugars were determined during a given night of sleep.

A total of 16 diabetic subjects was studied by means of hourly blood glucose determinations during the night. Of these, five were untreated, except by diet; eight were insulin-treated and three were orinase-treated diabetics.

\section{RESULTS}

The data shown in Table I summarize the hourly blood glucose concentrations found at night in the normal subjects and show that hourly variations in blood glucose concentration are small during sleep. The greatest variation of blood glucose in 


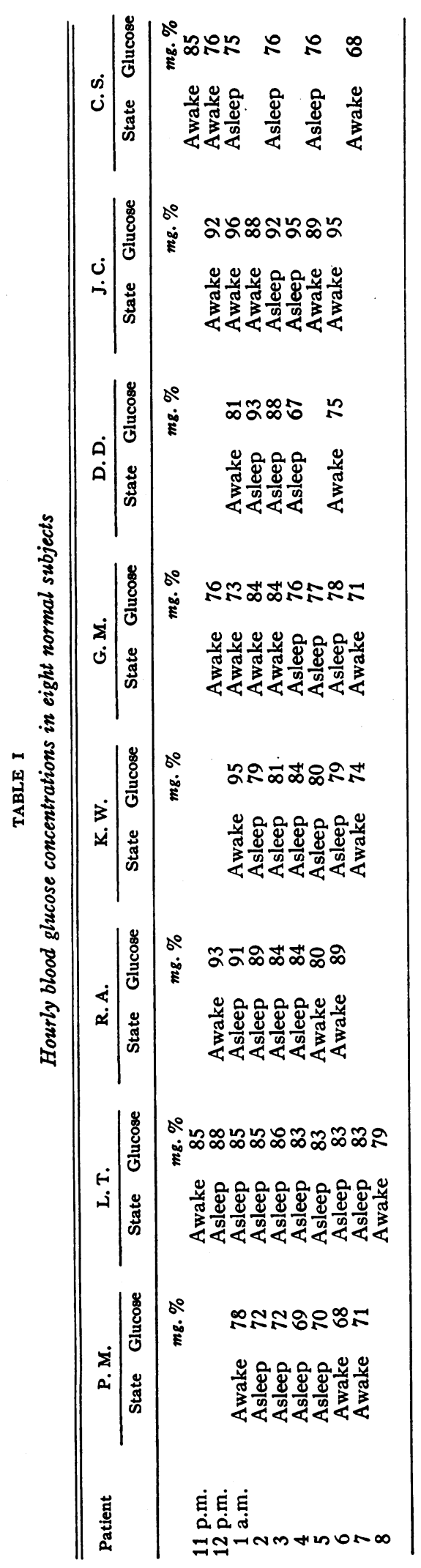

any normal subject was $26 \mathrm{mg}$. per cent. The mean standard deviation for the group as a whole was only $\pm 4.7 \mathrm{mg}$. per cent. Blood sugar concentrations during sleep are, therefore, characterized by their great constancy.

The hourly blood glucose concentrations on the diabetic subjects are summarized in Tables II, III and IV. These data indicate a much greater variability of blood glucose than is present in the normal subjects.

This variability may be most conveniently estimated by inspecting the data obtained on the untreated patients (Table II). In this group, the greatest variation of blood glucose concentration was $91 \mathrm{mg}$. per cent. The mean standard deviation of the group as a whole was $\pm 18.5 \mathrm{mg}$. per cent.

Many patterns of variation of blood glucose were found in the insulin-treated patients (Table III). Some of the more interesting patterns follow. Patient W.F. developed fairly severe hypoglycemia while asleep (blood glucose $32 \mathrm{mg}$. per cent). Despite hypoglycemia, he did not awaken. By morning, his blood glucose had returned to a normoglycemic level. Patient C.A. showed a progressive increase in blood glucose during the night, using from 155 to $293 \mathrm{mg}$. per cent during the night. Patient S.P. was hyperglycemic until 1:00 a.m. and from 1:00 a.m. until awaking in the morning he was normoglycemic. The nocturnal hyperglycemia was not reflected in the fasting morning blood glucose concentration. The greatest variation of blood glucose in any subject of this group was $140 \mathrm{mg}$. per cent and the mean standard deviation for the group as a whole was $\pm 27.5 \mathrm{mg}$. per cent.

The three orinase-treated patients showed a variability of blood glucose that was intermediate between the normal subjects and the untreated diabetics (Table IV). The mean standard deviation of hourly blood glucose concentrations in this group was $\pm 11.1 \mathrm{mg}$. per cent. Of interest are the data on Patient B.M. who was studied prior to and while on orinase therapy. Following orinase therapy, not only did the fasting blood glucose concentration fall but there was also a decrease in the variability of his hourly glucose concentration. 
TABLE II

Hourly nocturnal blood glucose concentrations in five subjects with diabetes mellitus treated by diet alone

\begin{tabular}{|c|c|c|c|c|c|c|c|c|c|c|}
\hline \multirow[b]{2}{*}{ Time } & \multicolumn{2}{|c|}{$\underset{\text { Untreated }}{\mathrm{J} . \mathrm{W}}$} & \multicolumn{2}{|c|}{ Untreated } & \multicolumn{2}{|c|}{$\underset{\text { Untreated }}{\text { R. C. }}$} & \multicolumn{2}{|c|}{$\begin{array}{l}\text { M. H. } \\
\text { Untreated }\end{array}$} & \multicolumn{2}{|c|}{$\begin{array}{c}\text { A. B. } \\
\text { Untreated }\end{array}$} \\
\hline & State & Glucose & State & Glucose & State & Glucose & State & Glucose & State & Glucose \\
\hline $\begin{aligned} & 11 \text { p.m. } \\
& 12 \text { p.m. } \\
& 1 \text { a.m. } \\
& 2 \\
& 3 \\
& 4 \\
& 5 \\
& 6 \\
& 7\end{aligned}$ & $\begin{array}{c}\text { Awake } \\
\text { Awake } \\
\text { Awake } \\
\text { Asleep } \\
\text { Asleep } \\
\text { Awake } \\
\text { Awake }\end{array}$ & $\begin{array}{c}\text { mg. } \% \\
121 \\
125 \\
121 \\
185 \\
120 \\
124 \\
113\end{array}$ & $\begin{array}{c}\text { Awake } \\
\text { Awake } \\
\text { Awake } \\
\text { Awake } \\
\text { Awake } \\
\text { Awake } \\
\text { Awake } \\
\text { Awake }\end{array}$ & $\begin{array}{c}m g . \% \\
204 \\
182 \\
164 \\
158 \\
175 \\
150 \\
152 \\
158\end{array}$ & $\begin{array}{l}\text { Awake } \\
\text { Asleep } \\
\text { Asleep } \\
\text { Asleep } \\
\text { Awake } \\
\\
\text { Awake }\end{array}$ & $\begin{array}{c}\text { mg. } \% \\
353 \\
319 \\
314 \\
271 \\
276\end{array}$ & $\begin{array}{c}\text { Awake } \\
\text { Awake } \\
\text { Awake } \\
\text { Awake } \\
\text { Awake }\end{array}$ & $\begin{array}{c}\text { mg. \% } \\
100 \\
102 \\
100 \\
84 \\
98\end{array}$ & $\begin{array}{c}\text { Awake } \\
\text { Awake } \\
\text { Awake } \\
\text { Awake } \\
\text { Awake } \\
\text { Asleep } \\
\text { Awake } \\
\text { Awake }\end{array}$ & $\begin{array}{c}m g . \% \\
150 \\
136 \\
138 \\
112 \\
122 \\
120 \\
116 \\
108\end{array}$ \\
\hline
\end{tabular}

\section{DISCUSSION}

The data presented in this paper establish that the hourly variation in blood glucose concentrations during sleep in normal subjects is extremely small. Blood sugar constancy during sleep must reflect an effective regulating mechanism since it is known that other factors capable of affecting glucose metabolism operate differently during sleep than during the waking state. For example, approximately 70 per cent of the daily adrenal secretion occurs between 12:00 midnight and 9 a.m. (10). Norepinephrine and epinephrine plasma levels are decreased during sleep (11). The constancy of blood glucose concentrations during sleep appears to be based on an effective regulating mechanism operating at a time when it does not have to deal with additional exogenous carbohydrates furnished by eating or increased glucose utilization produced by exercise.

In contrast, subjects with diabetes mellitus have blood glucose concentrations that are quite variable. This variability is present, first of all, in untreated diabetics. In some untreated patients, the variability may be explained by a decreased ability to utilize glucose. For example, Patient A.B. showed a progressive decline in hourly blood glucose concentrations from 11:00 p.m. to 6:00 a.m. the following morning. This decline may be related to impairment of glucose tolerance with the high glucose levels during the evening reflecting the hyperglycemic effects of the evening meal. On the other hand, Patients J.W. and M.H. showed spontaneous variations of blood glucose concentrations that could not be explained on this basis.
The greatest variability of blood glucose levels was found in the insulin-treated patients. A number of patterns of blood glucose variation was found which appear to be of clinical importance. The occurrence of hypoglycemia during sleep, without producing symptoms or arousal of the patient, is of obvious importance. This phenomenon has previously been reported by Maddock and Trimble (12). Patients who show significant hyperglycemia during a large part of the night, but who are normoglycemic by morning (Patient S.P.) would be considered well controlled by generally accepted criteria but, in truth, would be relatively uncontrolled for a significant portion of each 24 hours. Conversely, patients like C.A., whose glucose concentrations during sleep were considerably lower than during waking hours, might be overtreated on the basis of a morning blood sugar.

These data suggest that attempted diabetic regulation by means of urine glucose concentrations might be particularly unsatisfactory. Insulin dosages based on 24 hour glucose excretion might not correspond to the diurnal variations present in diabetics. Spot checks of urinary glucose might be even more unsatisfactory. For example, in Patient S.P. the morning urine would contain glucose that reflected nocturnal hyperglycemia. Such a patient would be given excessive insulin for his daytime needs.

It is important to emphasize that the diabetic patient is not only insulin-deficient but that he lacks an adequate mechanism for the regulation of blood glucose. In such patients, the physician attempts to substitute insulin in type and amount 


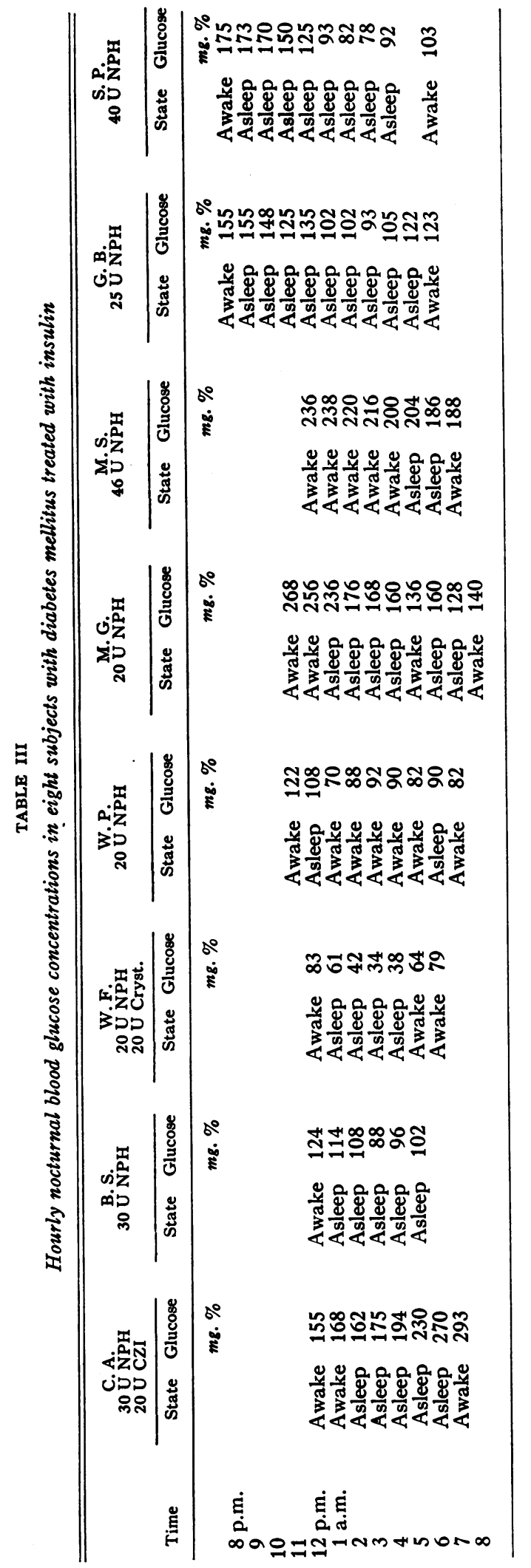

TABLE IV

Hourly nocturnal blood glucose concentrations in three subjects with diabetes mellitus treated with orinase

\begin{tabular}{|c|c|c|c|c|c|c|}
\hline \multirow[b]{2}{*}{ Time } & \multicolumn{2}{|c|}{$1.0 \underset{\text { (G.M. M.day) }}{\text { B. }}$} & \multicolumn{2}{|c|}{0.5 (G. C. } & \multicolumn{2}{|c|}{$\underset{0.5 \text { (Gm./day) }}{\text { M. H. }}$} \\
\hline & State & $\begin{array}{l}\text { Glu- } \\
\text { cose }\end{array}$ & State & $\begin{array}{l}\text { Glu- } \\
\text { cose }\end{array}$ & State & $\begin{array}{l}\text { Glu- } \\
\text { cose }\end{array}$ \\
\hline \multirow{8}{*}{$\begin{aligned} & 11 \text { p.m. } \\
& 12 \text { p.m. } \\
& 1 \text { a.m. } \\
& 2 \\
& 3 \\
& 4 \\
& 5 \\
& 6 \\
& 7 \\
& 8\end{aligned}$} & \multirow{8}{*}{$\begin{array}{c}\text { Awake } \\
\text { Awake } \\
\text { Awake } \\
\text { Awake } \\
\text { Awake } \\
\text { Awake } \\
\text { Awake } \\
\text { Awake }\end{array}$} & mg. $\%$ & & mg. \% & \multirow{7}{*}{$\begin{array}{l}\text { Awake } \\
\text { Asleep } \\
\text { Asleep } \\
\text { Asleep } \\
\text { Asleep } \\
\text { Awake } \\
\text { Awake }\end{array}$} & mg. $\%$ \\
\hline & & & Awake & 112 & & 130 \\
\hline & & 124 & Asleep & 100 & & 124 \\
\hline & & $\begin{array}{r}104 \\
94\end{array}$ & Asleep & 92 & & $\begin{array}{l}124 \\
106\end{array}$ \\
\hline & & 96 & Asleep & 76 & & 106 \\
\hline & & 100 & & & & 110 \\
\hline & & 94 & Awake & 72 & & 106 \\
\hline & & 106 & & & $\begin{array}{l}\text { Awake } \\
\text { Awake }\end{array}$ & $\begin{array}{l}118 \\
124\end{array}$ \\
\hline
\end{tabular}

that will keep the patient's blood glucose at physiologic levels. However, the physician substitutes a biochemical substance and not a physiologic mechanism. Insulin will be released from the site of injection at a rate not determined by changes in blood glucose but at a rate determined by the type and amount of insulin. Since blood glucose concentrations of patients are not usually determined during sleep, the discrepancies between insulin dosage and insulin need might be expected to be great during this time. If one accepts the concept of ideal control of diabetes mellitus as meaning that the blood sugar level of diabetic subjects should correspond to the diurnal curves of normal individuals, then obviously greater attention must be paid to the hours of sleep in diabetics.

The data on the orinase-treated patients showed less variation than the data on insulin-treated patients. These data should not be interpreted as indicating that orinase is superior to insulin as a form of therapy. The orinase-treated patients had less severe disease than the insulin-treated patients. Nor does a relatively constant blood glucose level necessarily indicate more effective cellular utilization of glucose.

\section{SUMMARY}

1. Normal subjects show essentially constant blood glucose concentrations during sleep.

2. Patients with diabetes mellitus show marked variations in blood glucose concentrations during sleep. 
3. Such variations have important therapeutic implications for the management of diabetic patients.

\section{REFERENCES}

1. Robin, E. D., Travis, D. M., Julian, D. G., Crump C. H., and Boshell, B. Blood sugar regulation during sleep in normal and diabetic subjects (abstract). J. clin. Invest. 1958, 37, 925.

2. Kleitman, N. Sleep and Wakefulness. Chicago, University of Chicago Press, 1939.

3. Robin, E. D. Some interrelations between sleep and disease. Arch. intern. Med. 1958, 102, 669.

4. Endres, G., and Lucke, H. Die Regulation des Blutzuckers und der Blutreaktion beim Menschen. $Z$. ges. exp. Med. 1925, 45, 669.

5. Chieffi, A., and Rosselli del Turco, L. Variazioni individuali nel bambino della curva glicemica e della curva lipemica in rapporto alla funzione del sonno. Riv. crit. Clin. med. 1937, 38, 208.

6. Trimble, H. C., and Maddock, S. J. The fluctuations of the capillary blood sugar in normal young men during a 24-hour period (including a discussion on the effect of sleep and of mild exercise). J. biol. Chem. 1929, 81, 595.

7. Dienst, C., and Winter, B. Schlaf, Blutzucker und Säurebasenhaushalt. Z. klin. Med. 1937, 133, 91.

8. Froesch, E. R., and Renold, A. E. Specific enzymatic determination of glucose in blood and urine using glucose oxidase. Diabetes 1956, 5, 1.

9. Nelson, N. A photometric adaptation of the Somogyi method for the determination of glucose. J. biol. Chem. 1944, 153, 375.

10. Tyler, F. H., Migeon, C., Florentin, A. A., and Samuels, L. T. The diurnal variation of 17-hydroxycorticosteroid levels in plasma (abstract). J. clin. Endocr. 1954, 14, 774.

11. Robin, E. D., Hamlin, J., Bromberg, P. A., and Forkner, C. E., Jr. Metabolic patterns during physiologic sleep: IV. Plasma catechols during sleep. To be published.

12. Maddock, S. J., and Trimble, H. C. Prolonged insulin hypoglycemia without symptoms. J. Amer. med. Ass. 1928, 91, 616. 